\title{
Public Urban Green Spaces' Visiting Habits and Perception Regarding Their Health Benefits in Addis Ababa City, Ethiopia
}

\author{
Girma Alemayehu Beyene ${ }^{1, \text { * }}$, Emawayish Nigussie Borishe ${ }^{2}$ \\ ${ }^{1}$ Department of Public Health, College of Medicine and Health Sciences, Wolkite University, Wolkite, Ethiopia \\ ${ }^{2}$ Department of Environment and Climate Change Management, Ethiopian Civil Service University, Addis Ababa, Ethiopia
}

Email address:

Girmalemayehu16@gmail.com (G. A. Beyene), n.emawayish@gmail.com (E. N. Borishe)

*Corresponding author

\section{To cite this article:}

Girma Alemayehu Beyene, Emawayish Nigussie Borishe. Public Urban Green Spaces' Visiting Habits and Perception Regarding Their Health Benefits in Addis Ababa City, Ethiopia. International Journal of Environmental Protection and Policy. Vol. 9, No. 3, 2021 , pp. 50-58. doi: $10.11648 /$ j.ijepp.20210903.11

Received: March 8, 2021; Accepted: May 21, 2021; Published: May 31, 2021

\begin{abstract}
Physical structure and activities undertaken at green spaces provide substantial health, social, environmental, psychological, and economic benefits to residents of an urban area. Study regarding the health benefits of green spaces in developing countries is very limited. Addis Ababa is the capital and the largest city in Ethiopia and not many studies on green spaces are available. Thus, this community-based cross-sectional study was conducted among 204 residents of Addis Ababa city. A multistage sampling technique was used, the sample size was allocated proportionally and selected by a simple random sampling technique. Data were coded and entered into Epi Info тм 7 and exported to SPSS version 25 for cleaning and analysis. Results showed that only $30 \%$ of the respondents visited green spaces in the last 12 months. The common reasons for the visit were to adore nature (30.4\%), refresh mind (25\%), and "breathe quality air" (20.6\%). Although most study participants were aware of the appealing psychological benefits of green spaces, only $55.9 \%$ of them had a positive perception regarding the health benefits of green spaces. Compared with the negative perception those with positive perception were more than twice more likely to visit green spaces (AOR: $2.51 ; 95 \%$ CI: 1.33-4.77). The study concluded that in addition to expanding the green spaces efforts have to be directed to solving challenges that discourage visits, increasing awareness, and improving the perception of the community regarding added health benefits of green spaces.
\end{abstract}

Keywords: Urban Green-Space, Parks, Perception, Health

\section{Introduction}

The urban green space (UGS) consists of spaces that are located in the urban web including recreational parks, urban forest, river buffer vegetation, avenues of trees, and other garden areas. These UGS offer a variety of multidimensional benefits to humans and are vital for the conservation of biodiversity. The World Health Organization (WHO) encourages the increasing of urban green spaces with a minimum standard of $9 \mathrm{~m}^{2}$ of green space per capita [1-6]. Physical structure and activities undertaken at public green spaces offer many benefits to urban residents contributing to health, social and economic gain. Although the mechanisms relating to green space and health are likely to be complex, interacting, and having a synergistic effect, studies on the issue suggested four pathways: improving air quality, boosting physical activity, reducing stress, and enhancing social interactions and cohesion [7-10].

Urban green spaces provide substantial social, environmental, psychological, health, economic benefits to metropolitan inhabitants, and contribute to their quality of life. These spaces may be used as leisure, amusement, sport, and recreational resources, safe and exciting play areas for children, and resting areas for elders. Green spaces may also deliver noteworthy environmental benefits of filtering noise, purifying air, mitigating high temperatures, and maintaining climate [3, 11-13].

The role of urban green spaces and parks in improving 
physical and mental health is all-embracing. They may provide a sense of tranquility and encourage the use of outdoor spaces. Gardening in green spaces may also help promote mental and psychological health and reduce stress [14-19]. In addition, recreational services provided at green spaces and parks may generate revenues and create employment opportunities for low-income neighborhoods, which may in turn reduce crime and aggressive anti-social behaviors [20-22].

Exposure to green space may affect morbidity and mortality from chronic cardiovascular diseases like stroke and respiratory diseases including cancers, possibly by inspiring physical activity, regulating weight, modifying stress, and social connectedness [23, 24]. Frequent exposure to green space would alter air pollution levels and lower the risk of lung cancer. Recent studies also revealed green space and parks would have an impact on birth outcomes. Since birth outcomes can be affected by stress, social capital, levels of physical activity, and exposure to pollution all of them can be mitigated by maternal exposure to the green spaces [14, 25-27].

Studies regarding the health benefits of urban green spaces are especially relevant to governments, organizations, and communities that are making efforts to introduce new or preserve existing green spaces. Understanding of the public regarding the health benefits of green spaces and parks deliver significant contributions to endorse participatory sustainable green space development $[25,28,29]$. In the past two decades green spaces in Addis Ababa city were serving the purpose they are not meant for; they were poorly managed with poor community and stakeholders' involvement [30-32].

However, in the recent two years, the Offices of the Prime Minister and Addis Ababa city administration are restoring the abandoned open spaces, creating new green spaces and parks in the city. In addition to Gullele Botanic Garden, Unity, and Entoto Parks which were completed and open for the public, the gigantic multimillion-dollar Sheger beautification park project is also on fast-track execution. The government has demonstrated great commitment and dedication more than ever for green space expansion and park development. For the effort to be fruitful, the community perception and understanding regarding the benefits of green spaces and parks, especially their health effect is of paramount relevance [33-35].

Nevertheless, studies concerned with understanding and perception of the community members regarding the health effects of urban green spaces and parks in developing countries are very limited. Accordingly, the objectives of this study were to assess the level of public visits to green spaces, challenges encountered while visiting green spaces, perception of the community about the health benefits of green spaces, and the association between the level of perception and the visiting habit. The finding of the study will be used to fill the perception gap identified and designing appropriate interventions in solving those challenges and problems. Additionally, it will be very helpful in designing participatory green space infrastructure development.

\section{Methods and Materials}

\subsection{Study Area and Period}

The study was conducted in Addis Ababa city in January 2020. Addis Ababa city is the capital of Ethiopia, with a total area of $540 \mathrm{~km}^{2}$, divided into ten sub-cities (Figure 1) and 117 Woredas (lower level of administration in the city). The altitude of Addis Ababa ranges from 2200 to 3100 meters above sea level with a mean annual rainfall of $1200 \mathrm{~mm}$. The most recent population projection estimate for the city was $3,434,000$ in July 2017. Green spaces, parks, and urban open spaces are managed under Environmental Protection and Green Development Authority of the city. Regarding the distribution of public green spaces and parks of the city, Gullele sub-city has the largest share of green spaces, followed by Nifas-Silk Lafto sub-city, Yeka sub-city, Kirkos sub-city, and Lideta sub-city [36, 37].

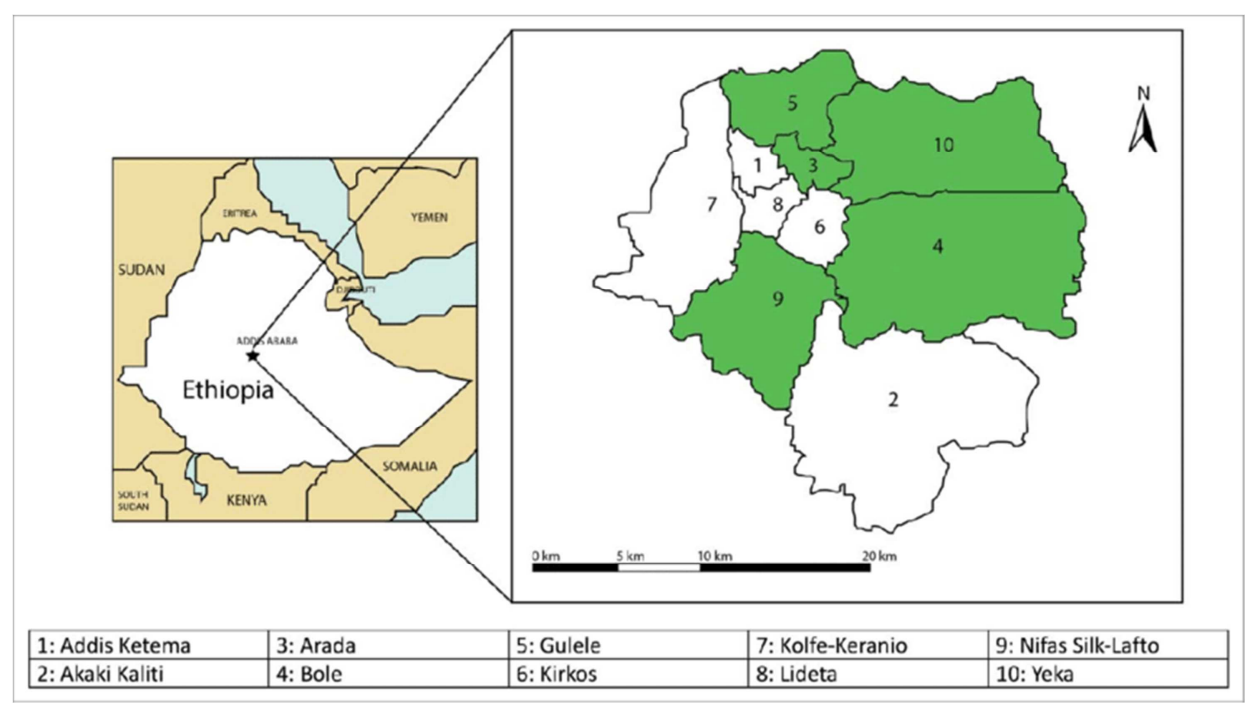

Figure 1. Map of the Addis Ababa city (Source: Addis Ababa city administration council, 2006). 


\subsection{Study Design and Population}

Community based descriptive cross-sectional study design was conducted among adults who are residents of Addis Ababa city for at least six months.

\subsection{Sample Size}

The required sample size for the study was calculated using Epi Info тм 7 StatCalc functions for population survey considering the $86 \%$ of residents visited urban green space from a previous study in a very comparable setting of Hawassa city [1] which gave the largest sample size. Using $95 \%$ CI and a $5 \%$ margin of error and considering a $10 \%$ non-response rate, a total of 204 final sample size was determined.

\subsection{Sampling Techniques and Procedure}

A multistage sampling technique was utilized. As a primary sampling unit from the ten sub-cities of Addis Ababa, three of them namely Yeka sub-city, Gullele sub-city, and Nifas-silk Lafto sub-city were randomly sampled. Woredas within the selected sub-cities were secondary sampling unit and the number of study participants from each of the woredas was allocated proportionally based on the total number of households in each woreda and they were selected by simple random sampling technique with excel generated random numbers using house numbers of the households as a sampling frame.

\subsection{Data Collection Techniques}

The questionnaire used for the study was developed after a wide-ranging review of the literature published related to the topic, first prepared in English and translated to local language Amharic, then translated back to English by the third person to check for its consistency and administered with the Amharic version. The questionnaire had three parts comprising: sociodemographic characteristics of study participants, visiting pattern of green spaces, and questions used to measure perception regarding health benefits of green spaces.

Five experienced Bachelor's degree holder enumerators were recruited and trained as data collectors and two of the seniors were selected as supervisors. Pretest was done before the actual data collection and necessary modification was made accordingly. The data was then collected through a household survey using the pretested questionnaires. During the data collection process, close supervision was made, filled formats and questionnaires were checked for completeness and consistency by the supervisors on daily basis.

\subsection{Data Processing and Analysis}

Once cross-checked, validated and all the discrepancies resolved, data were coded and double entered into Epi Info тм 7 and exported to SPSS (Statistical Package for Social Science) version 25 for cleaning and analysis. The perception was measured using six questions with 17 possible answers and those who answered the above mean value were categorized as having positive perception, the rest having negative perception [38]. Descriptive summary statistics like frequencies, percentages, means and standard deviations were calculated, Results were presented in texts, tables, and graphs. To assess the factors associated with visiting habit bivariate analyses were performed and those with a p-value less than 0.25 were nominated for multivariable analysis. In multivariable logistic regression adjusted odds ratio with its $95 \%$ confidence interval were used to judge for precision and decide whether independent statistically significant association exist or not.

\section{Results}

\subsection{Sociodemographic Characteristics of the Study Participants}

All the 204-sample sizes responded to the questions, making the response rate $100 \%$. The age of study participants ranges from 18-50 with the mean \pm standard deviation (SD) was $31.17 \pm 8.06$ years. Of the study participants, $52.9 \%$ of them were females and the remaining $47.1 \%$ were males. Three-fifth (59.8\%) of the study participants were married, $23.5 \%$ were single and $5.4 \%$ were widowed. Regarding the occupation, $43.6 \%$ were employed on monthly salaries and about a quarter $(26 \%)$ of them were self-employed. More than one-third (35.3\%) of the study participants were orthodox Christians, $28.9 \%$ of them were Muslims and $21.6 \%$ were followers of the Protestant religion. Concerning the educational status of the respondents, $38.7 \%$ attained at least college, $32.4 \%$ secondary educational status, $20 \%$ of them were in primary education and nearly $10 \%$ of the study participants did not have formal education. The monthly income of the family ranged from 1100-10,000 Ethiopian Birr (ETB) with the median \pm SD of $5469.50 \pm 2526$ ETB (Table 1).

\subsection{Visiting Pattern of Green Spaces}

The distance study participants need to walk from their home to reach the nearby green space ranges from 10 minutes to an hour, with a mean of 33 minutes and a standard deviation of 14 minutes. Sixty-two (30\%) of the respondents visited nearby green space at least once in the last 12 months; $37.1 \%$ of them visited every month, $22.6 \%$ visited every week and only $6.5 \%$ visited daily. However, two-fifths (39.7\%) of the respondents prefer to visit the green spaces and parks every week, $29.4 \%$ prefer to visit monthly, $18.6 \%$ of them prefer to visit green spaces on holidays and public festivals, and $3.9 \%$ of them were not interested to visit at all. Concerning the time they spent in the green space $40.3 \%$ of them were there for 30 minutes to an hour, $37.1 \%$ stayed for less than 30 minutes and only $8.1 \%$ of them spent more than two hours in the green spaces. 
Perception Regarding Their Health Benefits in Addis Ababa City, Ethiopia

Table 1. Sociodemographic characteristics of study participants in Addis Ababa, Ethiopia, 2020.

\begin{tabular}{|c|c|c|c|}
\hline Characteristics & Response category & Frequency & Percent \\
\hline \multirow{3}{*}{ Age } & $18-24$ & 55 & 27.0 \\
\hline & $25-35$ & 86 & 42.1 \\
\hline & $>35$ & 63 & 30.9 \\
\hline \multirow{2}{*}{ Sex } & Female & 108 & 52.9 \\
\hline & Male & 96 & 47.1 \\
\hline \multirow{3}{*}{ Marital status } & Single & 48 & 23.5 \\
\hline & Married & 122 & 59.8 \\
\hline & Divorced & 23 & 11.3 \\
\hline \multirow{5}{*}{ Occupation } & Employee & 89 & 43.6 \\
\hline & Housewife & 15 & 7.4 \\
\hline & Student & 13 & 6.4 \\
\hline & Self-employed & 53 & 26 \\
\hline & Daily laborer & 34 & 16.7 \\
\hline \multirow{3}{*}{ Religion } & Orthodox & 72 & 35.3 \\
\hline & Muslim & 59 & 28.9 \\
\hline & Catholic & 29 & 14.2 \\
\hline \multirow{5}{*}{ Educational status } & Can't read \& write & 5 & 2.5 \\
\hline & Read and write & 14 & 6.9 \\
\hline & Primary & 40 & 19.6 \\
\hline & Secondary & 66 & 32.4 \\
\hline & College and above & 79 & 38.7 \\
\hline \multirow{2}{*}{ Monthly income of the family in ETB } & Median \pm SD & $5469.50 \pm 2526$ & \\
\hline & Range & $1100-10000$ & \\
\hline
\end{tabular}

Table 2. Public green space visits among the study participants in Addis Ababa, Ethiopia, 2020.

\begin{tabular}{|c|c|c|c|}
\hline Characteristics & Response category & Frequency & Percent \\
\hline \multirow{2}{*}{$\begin{array}{l}\text { Distance of nearby green space from home in } \\
\text { walking minutes }\end{array}$} & Within 30 minutes & 84 & 41.2 \\
\hline & More than 30 minutes & 120 & 58.8 \\
\hline \multirow{2}{*}{ Visit green space } & Yes & 62 & 30.4 \\
\hline & No & 142 & 69.6 \\
\hline \multirow{5}{*}{ Frequency of visit $(n=62)$} & Daily & 4 & 6.5 \\
\hline & Several times a week & 11 & 17.7 \\
\hline & Weekly & 14 & 22.6 \\
\hline & Monthly & 23 & 37.1 \\
\hline & Occasionally & 10 & 16.1 \\
\hline \multirow{5}{*}{ Preferred visiting time } & Not at all & 8 & 3.9 \\
\hline & Daily & 17 & 8.3 \\
\hline & Weekly & 81 & 39.7 \\
\hline & Monthly & 60 & 29.4 \\
\hline & Holidays & 38 & 18.6 \\
\hline \multirow{3}{*}{ Time stayed in green space $(n=62)$} & Less than 30 Minutes & 23 & 37.1 \\
\hline & $1-2$ hours & 9 & 14.5 \\
\hline & More than 2 hours & 5 & 8.1 \\
\hline \multirow{8}{*}{$\begin{array}{l}\text { Reasons of visit } \\
\text { (Multiple answers possible) }\end{array}$} & Adore nature & 62 & 30.4 \\
\hline & Refresh mind & 51 & 25 \\
\hline & Breath quality air & 42 & 20.6 \\
\hline & Physical exercise & 25 & 12.3 \\
\hline & Spend with friends & 25 & 12.3 \\
\hline & Read books & 23 & 11.3 \\
\hline & Play with children & 11 & 5.4 \\
\hline & Source of income & 4 & 2 \\
\hline \multirow{5}{*}{$\begin{array}{l}\text { Challenges encountered in green space } \\
\text { (Multiple answers possible) }\end{array}$} & No other recreational services & 110 & 53.9 \\
\hline & Lack of transport & 65 & 31.9 \\
\hline & No major challenge & 47 & 23 \\
\hline & Increased crowding & 11 & 5.4 \\
\hline & Noise pollution & 9 & 4.4 \\
\hline \multirow{2}{*}{ Perception of safety visiting green spaces } & Yes & 98 & 48 \\
\hline & No & 106 & 52 \\
\hline
\end{tabular}




\begin{tabular}{llll}
\hline Characteristics & Response category & Frequency & Percent \\
& Lack of services & 59 & 41.5 \\
Reasons for failing to visit green spaces & Shortage of time & 42 & 29.6 \\
$(\mathrm{n}=142)$ & Not accessible & 25 & 17.6 \\
& Don't think important & 8 & 5.6 \\
& Not affordable & 8 & 5.6 \\
\hline
\end{tabular}

The common reasons the study participants visited the green space were to adore nature $(30.4 \%)$, refresh their mind (25\%), "breath quality air" $(20.6 \%)$, spend time with friends $(12.3 \%)$ and $11.3 \%$ of them love reading books in green spaces. More than half (53.9\%) of the respondents considered the lack of other recreational services in the green space as a major challenge followed by the lack of transport service to access the green spaces (31.9\%). Among those who failed to visit the green space, lack of related services (41.5\%), shortage of time $(29.6 \%)$ and lack of awareness about the importance of green spaces $(5.6 \%)$ were the top reasons for failure to visit the nearby green spaces (Table 2).

The common criteria determining the decision to visit urban green space include the availability of additional recreational services $(32.8 \%)$, accessibility of the green space $(24 \%)$, and attractiveness of the area $(20.6 \%)$ among others (Figure 2).



Figure 2. Criteria determining the decision to visit urban green spaces among study participants in Addis Ababa, 2020.

Table 3. Perception regarding the health benefits of green space among the study participants in Addis Ababa, 2020.

\begin{tabular}{llll}
\hline Characteristics & Response category & Frequency & Percent \\
\hline \multirow{2}{*}{ Think of green space to be important } & Yes & 183 & 89.7 \\
& No & 21 & 10.3 \\
& Aesthetic value & 180 & 88.2 \\
& Reduce stress & 171 & 83.8 \\
& Purify air & 169 & 82.8 \\
& Regulate temperature & 160 & 78.4 \\
& Encourage exercise & 135 & 66.2 \\
Health benefits of green space & Reduce cardiovascular diseases & 65 & 31.9 \\
(Multiple answers possible) & Filter noise & 53 & 26 \\
& Protect from flood & 47 & 23 \\
& Create employment opportunity & 45 & 22.1 \\
& Reduce diabetes & 44 & 21.6 \\
Consider the need of creating new green space & Yes & 33 & 16.2 \\
Favor of using the budget for a park project & No & 29 & 14.2 \\
Ses & No & 132 & 64.7 \\
& Yes & 72 & 35.3 \\
Ready to volunteer in green spaces & No & 110 & 53.9 \\
Perception of health benefits green space & Yes & 94 & 46.1 \\
\hline
\end{tabular}




\subsection{Perception Regarding the Benefits of Green Space}

Nine in ten $(90 \%)$ of the study participants think green space to be important and worth considering in the urban setting. However, ten percent of the study participants did not contemplate urban green spaces to be important, and more than one-third $(35.3 \%)$ of study participants did not consider it important to have green space in their proximity. At least six of the nine $(66 \%)$ of the study participants knew the common benefits of green spaces in beautifying the environment, relieving stress, purifying polluted air, regulating environmental temperature, and encouraging physical exercise and fitness. Less than a quarter of the study participants knew its benefits of reducing the risk of chronic diseases like diabetes mellitus, its relevance in creating employment opportunities, and social interaction. More than half $(53.9 \%)$ of the study participants were in favor of using the government budget for green space and park projects. Only $55.9 \%$ of the study participants had a positive perception towards the health benefits of urban green space and parks, and the remaining had a negative perception (Table 3).

\subsection{Factors Associated with the Habit of Visiting Green Spaces}

Controlling for the sociodemographic characteristics and other related variables, the level of perception study participants had regarding health benefits of green space was found to have a statistically significant independent association with the visiting habit of green spaces. Study participants with positive perception were more than twice more likely to visit green spaces compared to those who had negative perception (AOR: 2.51 ; 95\% CI: 1.33-4.77). There is no statistically significant association between the sociodemographic characteristics of the study participants and their visiting habits (Table 4).

Table 4. Factors associated with the visiting habits of public green spaces in Addis Ababa, 2020.

\begin{tabular}{|c|c|c|c|c|c|c|}
\hline \multirow{2}{*}{ Characteristics } & \multirow{2}{*}{ Response category } & \multicolumn{2}{|c|}{ Visited green space } & \multirow{2}{*}{$\operatorname{COR}[95 \% \mathrm{CI}]$} & \multirow{2}{*}{ AOR $[95 \%$ CI] } & \multirow{2}{*}{ P-value } \\
\hline & & Yes & No & & & \\
\hline \multirow{3}{*}{ Age group } & $18-24$ & 22 & 33 & $1.54(0.72-3.31)$ & $1.72(0.79-3.78)$ & 0.175 \\
\hline & $25-35$ & 21 & 65 & $0.75(0.36-1.55)$ & $0.80(0.38-1.68)$ & 0.556 \\
\hline & $>35$ & 19 & 44 & 1 & 1 & \\
\hline \multirow{2}{*}{ Sex } & Male & 25 & 71 & $0.68(0.37-1.24)$ & $0.67(0.36-1.25)$ & 0.209 \\
\hline & Female & 37 & 71 & 1 & 1 & \\
\hline \multirow{4}{*}{ Occupation } & Housewife & 4 & 11 & $0.58(0.15-2.24)$ & $0.43(0.09-1.96)$ & 0.275 \\
\hline & Student & 6 & 7 & $1.39(0.38-5.04)$ & $0.93(0.21-4.04)$ & 0.919 \\
\hline & Self-employed & 14 & 39 & $0.58(0.23-1.46)$ & $0.62(0.21-1.78)$ & 0.370 \\
\hline & Daily laborer & 13 & 21 & 1 & 1 & \\
\hline \multirow{5}{*}{ Educational status } & Can't read and write & 1 & 4 & $0.85(0.09-8.07)$ & $0.59(0.06-5.88)$ & 0.660 \\
\hline & Read and write & 5 & 9 & $1.89(0.56-6.33)$ & $1.51(0.42-5.51)$ & 0.529 \\
\hline & Primary & 15 & 25 & $2.03(0.89-4.66)$ & $2.08(0.87-4.97)$ & 0.098 \\
\hline & Secondary & 23 & 43 & $1.81(0.87-3.76)$ & $1.56(0.71-3.43)$ & 0.268 \\
\hline & College and above & 18 & 61 & 1 & 1 & \\
\hline $\begin{array}{l}\text { Walking distance from } \\
\text { home to green space }\end{array}$ & More than 30 minutes & 32 & 88 & 1 & 1 & \\
\hline \multirow{2}{*}{ Perception } & Positive & 44 & 70 & $2.51(1.33-4.77)$ & $2.51(1.33-4.77) *$ & 0.005 \\
\hline & Negative & 18 & 72 & 1 & 1 & \\
\hline
\end{tabular}

*: significant at $\mathrm{p}$-value $<0.05$

\section{Discussion}

This study analyzed the pattern of visiting green space and the perception of the community towards the health benefits of green space. The finding indicated that only a third of the study participants visited the green space within the last 12 months, which is very much lower than the study conducted in Hawassa city, Southern Ethiopia where $86 \%$ of the residents visited nearby green spaces. The difference might be attributed to the fact that Hawassa city is more of a tourist attraction site and recreational city, where residents are inclined to visit recreational centers including green space [1]

As per the result of the study, the commonest criteria determining the decision to visit green space and the most common challenge faced while visiting green spaces were the absence of other related recreational services. This is consistent with the study conducted in Hawassa city where most of the study participants complained about the absence of recreational services like cafeteria, shelter, toilet, and parking service around the public green spaces and parks [39]. This revealed that in addition to expanding the green spaces, attention has to be given to services provided at the green spaces.

Services ranging from a toilet to café and shops can be very helpful in increasing the number of visitors and frequency of visits to the green spaces and parks. Additionally, those services not only let the visitors stay longer in the area but also create jobs and are used as income generating opportunities for unemployed youngsters. Hence, solving the challenges would be very important for gaining health and economic benefits from the green spaces. Besides, making the green spaces more accessible, attractive, and 
safer would increase the visiting habit of the residents and associated benefits. In this regard, planting edible trees like Avocado and Mango would improve the attractiveness of the areas, may generate income, and contribute to the food security of the community in the long run.

The result of the study revealed most study participants were aware of the appealing psychological and environmental benefits of green spaces. However, few of them understand its relevance in promoting health and preventing chronic noncommunicable diseases. This is consistent with the study conducted in Bahir Dar and Hawassa cities where most of the study participants were aware of the aesthetic value of green spaces [15, 39]. This requires that effort be directed to increasing the awareness and understanding of community members regarding added health benefits of green spaces.

According to the World Health Organization (WHO), the number of obese children and adolescents has increased more than ten-fold in the past four decades with much faster growth in the low-and middle-income countries [40]. To overcome this problem, it is recommended to increase green spaces that permit children to be active through play, recreation, and sports As a result, community members should be encouraged to utilize the green spaces for performing physical activity and facilitating social contact as a remedy for the recent surge in the rate of obesity and overweight in the cities [25, 41].

Approximately half of the study participants did not feel a sense of ownership for the nearby green spaces. This is consistent with the study conducted in Ghana where the level of ownership and participation was low [42]. Involving the community in every step including planning and management of the green space and park development is essential, as it will make them feel possession of the spaces and likely to increase their visiting pattern. In addition, they will also expect to benefit from it economically and beyond, which will increase the protection and preservation of the green spaces and improve a sense of ownership.

According to the result of the study, only about half of the participants were in favor of using the government budget for green space development projects. This finding is lower than the study conducted in Greece, where most of the study participants were not only in favor of using government budget but were also willing to pay to support green space projects [16]. The difference might be due to the difference in the study setting and different levels of knowledge and understanding about the benefits of green spaces.

In this study, slightly more than half of the study participants had a positive perception regarding the health benefits of urban green space, which is lower than the study conducted in Hawassa and Bahir Dar cities where four in five of the study participants had positive perception regarding the benefits of the green spaces [38]. Improving perception regarding the multidimensional benefits of green space would increase the level of visits to green spaces, improve participation in green space development projects and their protection. Furthermore, it is relevant in realizing multiple sustainable development goals (SDG). SDG-11 making inclusive, safe, and resilient cities, SDG-13 combating climate change and its impact, and SDG-15 sustainable use and management of ecosystem and forest are directly related to expansion and utilization of public green spaces [35, 4345].

As a limitation of the study, the result of the study might be affected by the possibility of recall bias, the study participants may forget their actual practice. As the visiting pattern of green spaces was accessed within the last 12 months, they may forget to recall their visiting status because of the long duration and absence of opportunity to validate the response.

\section{Conclusion}

Despite the recent determination of the government in expanding green spaces and making them more accessible, a low proportion of residents visit those spaces. A significant percentage of study participants had a negative perception regarding the health benefits of green areas and spaces. In addition to expanding the green spaces, efforts have to be directed to solving the challenges encountered, increasing awareness, and improving perception and understanding of the community regarding added health benefits of green spaces. This requires the multisectoral collaboration of stakeholders working on improving living conditions and the wellbeing of the society. Inclusive health education should be disseminated to the public regarding the role of green spaces in health promotion and disease prevention especially how simple, efficient, and cost-effective it is in preventing the recent surge of overweight, obesity, and related noncommunicable cardiovascular diseases.

\section{List of Abbreviation}

AOR Adjusted Odds Ratio;

CI: Confidence Interval;

COR: Crude Odds Ratio;

ETB: Ethiopian Birr;

IRB: Institutional Review Board;

SD: Standard Deviation;

SDG: Sustainable Development Goals;

SPSS: Statistical Package for Social Science;

UGS urban green space;

WHO: World Health Organization

\section{Declarations}

\section{Ethical Approval and Consent to Participate}

Ethical approval was obtained from Wolkite University Institutional Review Board (IRB) and support letters were issued to Addis Ababa city administration Environmental Protection and Green Development Authority. In addition, after elaborating the purpose of the study informed written consent was obtained from the study participants. 


\section{Consent for Publication}

Not applicable.

\section{Availability of Data and Material}

The datasets used and/or analyzed during the current study are available from the corresponding author on reasonable request.

\section{Competing Interests}

All the authors do not have any possible conflicts of interest.

\section{Funding}

No funding was obtained for this study.

\section{Author's Contributions}

GA: involved in the design of the study, acquisition of data, analysis, and interpretation of results, drafted, reviewed the manuscript, and gave final approval of the version to be published.

EN: involved from the inception to design of the study, proposal development, acquisition, and analysis of data, reviewed the manuscript, and gave final approval of the version to be published.

\section{Author's Information}

GA: Assistant Professor of Epidemiology, Department of Public Health, College of Medicine and Health Sciences, Wolkite University, Ethiopia.

EN: MSc, Department of Environment and Climate Change Management, Ethiopian Civil Service University, Addis Ababa, Ethiopia.

\section{Acknowledgements}

We would like to acknowledge the study participants, data collectors, and supervisors whose contribution realized this study. We are thankful to our families whose unceasing care always encouraged us.

\section{References}

[1] Molla, Ikporukpo, and Olatubara, Utilization Patterns of Urban Green Infrastructure in Southern Ethiopia. J. Appl. Sci. Environ. Manage, 2017. 21 (7): p. 1227-1236.

[2] Rigolon, A., et al., Access to Urban Green Space in Cities of the Global South: A Systematic Literature Review. Urban Science, 2018. 2 (67).

[3] Sinnett, D., et al., Green Infrastructure Research into Practice. Centre for Sustainable Planning and Environments, University of the West of England, Bristol, 2016.

[4] World Health Organization, W., Urban green spaces and health. Copenhagen: WHO Regional Office for Europe. 2016.
[5] Lepczyk, C. A., et al., Biodiversity in the City: Fundamental Questions for Understanding the Ecology of Urban Green Spaces for Biodiversity Conservation. BioScience 2017. 67 (9): p. 799-807.

[6] Aronson, M. F., et al., Biodiversity in the city: key challenges for urban green space management. Front Ecol Environ, 2017. 15 (4): p. 189-196.

[7] Nasution, A. D. and W. Zahrah, Community perception on public open space and quality of life in Medan, Indonesia. Procedia-Social and Behavioral Sciences, 2014. 153: p. 585594.

[8] World Health Organization, W., Urban Green Space Interventions and Health. 2017.

[9] Frumkin, H., Urban sprawl and public health. Public health reports, 2016.

[10] Lee, A. C. and R. Maheswaran, The health benefits of urban green spaces: a review of the evidence. Journal of public health, 2011.33 (2): p. 212-222.

[11] Venhari, A. A., M. Tenpierik, and A. M. Hakak, Heat mitigation by greening the cities, a review study. Environment, Earth and Ecology, 2017. 1 (1): p. 5-32.

[12] Venkataramanan, V., et al., A systematic review of the human health and social well-being outcomes of green infrastructure for stormwater and flood management. Journal of environmental management, 2019. 246: p. 868-880.

[13] Bowen, K. J. and M. Parry, The evidence base for linkages between green infrastructure, public health and economic benefit. Paper prepared for the project Assessing the Economic Value of Green Infrastructure, 2015.

[14] Thompson, C. W., et al., More green space is linked to less stress in deprived communities: Evidence from salivary cortisol patterns. Landscape and urban planning, 2012. 105 (3): p. 221-229.

[15] Gashu, K. and T. Gebre-Egziabher, Public assessment of green infrastructure benefits and associated influencing factors in two Ethiopian cities: Bahir Dar and Hawassa. BMC Ecology, 2019. 19 (16).

[16] Latinopoulos, D., Z. Mallios, and P. Latinopoulos, Valuing the benefits of an urban park project: A contingent valuation study in Thessaloniki, Greece. Land Use Policy, 2016. 55: p. 130-141.

[17] Gascon, M., et al., Mental Health Benefits of Long-Term Exposure to Residential Green and Blue Spaces: A Systematic Review. International Journal of Environmental Research and Public Health, 2015. 12 (4): p. 4354-4379.

[18] Bratman, G. N., et al., Nature and mental health: An ecosystem service perspective. Science Advances Review, 2019.

[19] Sugiyama, T., et al., Associations of neighbourhood greenness with physical and mental health: do walking, social coherence and local social interaction explain the relationships? Journal of Epidemiology \& Community Health, 2008. 62 (5): p. e9-e9.

[20] Zupancic, T., et al., Green city: Why nature matters to healthAn Evidence Review. Toronto, Ontario. Toronto Public Health, 2015. 
[21] Vargas-Hernández, J. G., K. Pallagst, and J. ZdunekWielgołaska, Urban green spaces as a component of an ecosystem. Functions, services, users, community involvement, initiatives and actions. Revista de Urbanismo 2017. 37: p. 126.

[22] Beery, T., Engaging the private homeowner: Linking climate change and green stormwater infrastructure. Sustainability, 2018. 10 (12): p. 4791.

[23] Bedimo-Rung, A. L., A. J. Mowen, and D. A. Cohen, The significance of parks to physical activity and public health: a conceptual model. American journal of preventive medicine, 2005. 28 (2): p. 159-168.

[24] Maas, J., et al., Social contacts as a possible mechanism behind the relation between green space and health. Health \& place, 2009. 15 (2): p. 586-595.

[25] Kondo, M. C., et al., Urban Green Space and Its Impact on Human Health. International Journal of Environmental Research and Public Health, 2018. 15 (3): p. 445.

[26] Hu, Z., J. Liebens, and K. R. Rao, Linking stroke mortality with air pollution, income, and greenness in northwest Florida: an ecological geographical study. International journal of health geographics, 2008.7 (1): p. 20.

[27] Maas, J., et al., Morbidity is related to a green living environment. Journal of Epidemiology \& Community Health, 2009. 63 (12): p. 967-973.

[28] Mitchell, R. and F. Popham, Effect of exposure to natural environment on health inequalities: an observational population study. The lancet, 2008. 372 (9650): p. 1655-1660.

[29] Pinder, R., et al., Exploring perceptions of health and the environment: a qualitative study of Thames Chase Community Forest. Health \& place, 2009. 15 (1): p. 349-356.

[30] Tassew, A. and A. S. Nair, Analysis of public green spaces in Kolfe Keraniyo subcity, Addis Ababa, Ethiopia. Journal of Aquatic Biology and Fisheries, 2014. 2 (2): p. 7-15.

[31] Kefelew, G. and T. Lika, Challenges and Opportunities for the Development and Management of Urban Green Areas in Addis Ababa: The Case of Cooperative Housing Green Areas and Street Trees in Nifas Silk Lafto Sub-City, in Handbook of Research on Social, Economic, and Environmental Sustainability in the Development of Smart Cities, A. Vesco and F. Ferrero, Editors. 2015.

[32] Gebremeskel, G., The Status of Green spaces and Green space Participatory Management in the City of Addis Ababa, in Urban Environmental Management. 2014, ERASMUS-IHS University: Rotterdam, The Netherlands.
[33] G/wold, Y., Assessment of Public Leisure Services provision: The Case of Addis Ababa Recreational Parks, in Tourism and development. 2011, Addis Ababa.

[34] Girma, Y., et al., Urban green infrastructure planning in Ethiopia: The case of emerging towns of Oromia special zone surrounding Finfinne. Journal of Urban Management, 2019. 8 (75-88).

[35] Hernandez, J. G. V., K. Pallagst, and P. Hammer, Urban Green Spaces as a Component of an Ecosystem Functions, Services, Users, Community Involvement, initiatives and Actions. International Journal of Environmental Sciences \& Natural Resources, 2018.8 (1).

[36] Federal Democratic Republic of Ethiopia Central Statistical Agency, C. E., Population Projection of Ethiopia for All Regions At Wereda Level from 2014-2017. 2013.

[37] Gebre, T., et al., Current status and management practice of urban green spaces in Addis Ababa: A reflection on their potential for carbon sink. 2016.

[38] Gashu, K., T. Gebre-Egziabher, and M. Wubneh, Local communities' perceptions and use of urban green infrastructure in two Ethiopian cities: Bahir Dar and Hawassa. Journal of Environmental Planning and Management, 2019. 63 (2): p. 287-316.

[39] Hailegiorgis, Y. G., Recreational Parks: Practices and Challenges in Hawassa City. Journal of Tourism \& Hospitality, 2017. 6 (3).

[40] World Health Organization; WHO, World health statistics 2018: monitoring health for the SDGs, sustainable development goals. Geneva: 2018.

[41] Coombes, E., A. P. Jones, and M. Hillsdon, The relationship of physical activity and overweight to objectively measured green space accessibility and use. Social science \& medicine, 2010. 70 (6): p. 816-822.

[42] Mensah, C. A., et al. Community participation in urban planning: the case of managing green spaces in Kumasi, Ghana. in Urban Forum. 2017. Springer.

[43] Global Green Growth Institute, Green City Development Guidelines, in GGGI Technical Guideline No. 2,. 2016.

[44] Mensah, C. A., Sustaining urban green spaces in Africa: a case study of Kumasi Metropolis, Ghana, in Centre for Urban and Regional Studies; School of Geography, Earth and Environmental Sciences. 2015, University of Birmingham.

[45] Lois Jensen (editor) and U. United Nations, The Sustainable Development Goals Report. 2017, United Nations, UN. 